\title{
On the definition of the objectives of educational space in the contemporary globalizing world
}

\author{
Sergey E. Shishov ${ }^{1, *}$ \\ ${ }^{1}$ Institute of social and humanitarian technologies MSUTM named after. K. G. Razumovsky, 109004, Moscow, Russia
}

\begin{abstract}
On the basis of a civilized approach in an attempt to understand where and why it is necessary to seek the Russian educational space in ever-changing external conditions, this report analyzes the changes in the educational space of Russia, which occur under the severe pressure of globalization trends and the emergence of the information society. The author argues that at this stage it is important to determine the goals and values such that globalization is not degenerated into an equal dialogue of original cultures and the active, sometimes "knee jerk" imposition of modern ideals of the consumer society and Western values in other cultures. We consider binary oppositions in education: education that cares for culture and has a practical function. It is shown that in contrast to technological civilization comes an anthropocentric civilization, the basic idea of which is the presence of the human dimension in any knowledge about nature, society and their knowledge. Development of future strategies for the development of educational space of Russia, aiming to restart the system of values is already killing our civilization - it is here that is the most difficult but also the most important issue. It is proved that the purpose of renewal of education should focus on the transition from utilitarian and pragmatic education that focused largely on knowledge, skills and competences, to the humanist - education for personal development.
\end{abstract}

\section{Introduction}

In Russia, at least during the last 25 years, not only pedagogues-scientists, but teachers-practitioners regularly discuss the need for changes in education goals. There are at least two reasons, but each individually can give rise to a crisis in the education system: the change of the social system and the explosive development of information and communication technologies (ICT).

We discuss the systemic changes in the external environment for the formation and, consequently, require systemic changes in education, the main structural components of the education system: the meaning, purpose, content, forms and methods of teaching [1].

In fact, in recent years we have witnessed that under the guise of extension of variability the refusal to normalize the content of education at the federal level, the growth of cynicism, both among teachers and in the student's community, accelerating the pace of studying the content of education, the disunity of the teacher and the pupil, the devaluation of the spiritual and moral human values, the dominance of the ideals of western civilization, etc.. But all of this is the consequence of mechanisms or reformatting the Great Russian education.

And what about the meanings and purposes? The purpose of this article is to try to understand where and why it is necessary to seek for the Russian educational space in ever-changing external conditions.

\section{What is the problem?}

So far, mass public pedagogical consciousness (according to our estimates, up to $75 \%$ of teaching staff) is not pressured by the idea that the existing education does not meet the needs of post-industrial society and innovative economy, as well as it does not meet the latest achievements of science and technology with ICT in the first place. About $90 \%$ of parents of students, according to our estimates, live in the paradigm, "our children should be taught as we were taught" [2].

As a result, the task of education: support for innovative social and economic development still remains the declaration; its ability to meet the social demands of society often exists only on paper in the official reports of directors and rectors; pulling up to the demands of global competition is not scrutinized.

At the state level, in the relevant documents, quite appropriate statements on the conditions necessary for the implementation of new educational functions are made. They include variation of content and variability of forms of education, integration of learning processes in the production area, stimulation of creativity, leadership and initiatives, enhancement of institutional

* Corresponding author: seshishov@mail.ru 
diversity and individual access to educational resources, a focus on lifelong education and, as a consequence, customisation of educational trajectories, refusal of the culture of consumption, the formation of the impact of culture, creativity, innovation, dynamic adjustment of formed competences according to the rapidly changing demands of society and industry, a fundamental change in the roles and tasks of teachers, introduction of new education technologies, including ICT, transparency, interaction with all social institutions of society, reducing the role of the state in education [3].

However, we sadly have to admit that all this is nothing more than a mechanism, but not the essence and purpose of education.

More specifically, we mean the following. The idea, which would allow us to say it is of a qualitatively new order, a qualitative change in education, has not been revealed yet. There is no strategic outcome and strategic goal of a new system of education in Russia. Everything is presented as a change in the existing education system. This will not lead to its qualitative change, transformation to solve fundamentally new problems of today. Calls for the modernization of education look like an end in itself, because the driving force of change it is not disclosed. Consolidation of universities and schools are certainly quantitative rather than qualitative changes that lead to extensive rather than intensive development.

The main theme of the changes in the education system is a structural transformation; measures for the modification of material and a technical base and organizational and management structure. They are, of course, necessary and important, but they cannot determine the reform of education, as do not stipulate progressive qualitative transformations and changes. It is considered that in this case evolutionary, axiological, mental problems of Russian education will be solved by themselves.

\section{Whither does the Russian educational space move?}

In Russia socio-economic objectives for the formation of a qualitatively new development direction are stated. This is the achievement of the same welfare standards as in developed countries. It is the preservation and maintenance of a favourable human environment. This is the decline of economic differentiation of the population. All this happens against the background of the emerging knowledge economy. Thus, the level of intellectual development of citizens, their focus on obtaining new knowledge, creative use of intellectual plant, the active development of creative abilities, the capitalization of human potential should be placed at the corner-stone as the most important state priorities [4].

That is why the debate about the "quality of education" still continues to nowadays, although the value of this concept has appeared even in the Federal Law "On Education in the Russian Federation" (p. 29, Article 2). As soon as meaning and goals of the educational space change, its quality becomes inappropriate.
If we consider quality from the standpoint of philosophy, it is a complex category that represents some educational systems, environment, space, pattern, practice, object, subject, having a set of properties, characteristics. They all exist in unity and inseparable from each other, are shown in interaction with other objects, phenomena, space, systems. Thus, it is a statement of the existence of a complex of certain features. In a philosophical sense educational space, in fact, it is the creation of quality - a combination of characteristics that are not evaluative.

The quality of education begins obtaining evaluative character in the economy, when the quality of education is customized to the product or service quality.

Today, changes in the educational space of Russia come under severe pressure from globalization trends and the emergence of the information society. At this stage it is important to determine the goals and values. The first option is as follows. If these changes take place within the framework of the established values of a modern technically advanced civilization, it should be based on these values and save them. If we understand the information society as a simple transitional stage to a new type of cultural development, we should proceed to a radical revision of the former fundamental values. Various valuates of these changes involve the differentiation of the aims of education and the development strategies of educational space.

Many facts witness that we are going through a next stage of cultural change.

To date, scientists distinguish two types of cultural development in the history of development of human society - traditionalist and science and technology. The latter (in the literature it is sometimes called a technogenic type of development (Stepin VS) [5], sometimes it is defined by the vague word "West") - is lightning-fast by historical standards, changes in substantive human environment, extremely rapid modifying social relations and forms of social communities, communication mechanisms and methods of human communication, etc. traditionalist type of cultural development (in the traditional cultures change and innovation have never been considered valuable, it was important to follow the precepts of the ancestors, following the behaviour of the heroes) can be seen up to now, despite the attempt to eliminate it from the scientific-technological types of civilizations (such as the extermination of the Native Americans). These two types of civilization coexist, interact and vary, for example, in Japan, China, India, Argentina, and Brazil. There they are transformed into scientific and technological communities, while maintaining the specific features of identity. [6]

The basic values that characterize the culture of these two types of civilization disclose their fundamental differences. As a consequence, this leads to different ways of development and socialization, training and education.

In the traditional paradigm education is based on the idea of conservative-saving function of educational space. Important transmission of cultural heritage, knowledge, skills, ideals and values that promote 
creative personal development and the preservation of social predictability society is important. The content of education is based on the time-tested values of established knowledge and skills.

In the scientific and technological civilization type rationalist paradigm of education is not based on the content of education. "Behavioural repertoire" and effective ways of acquiring by students a wide range of knowledge (for instance, the concept of social engineering by B. Skinner), translating the goals of education, for example, according to R. Major, the language of pragmatic behavioural terms, the language of "measurable units of behaviour" (the prototype competences) are important for it.

Today it is important to realize that it is the scientific and technological civilization of the type of acceleration that leads mankind to the global crisis, both in the moral spheres, and environmental (in the broadest sense of the word). Mankind approaches the threshold of its selfdestruction. Globalization degenerated not into an equal dialogue of original cultures, but the active, sometimes rough (a series of colour revolutions) propagation of the ideals of modern consumer society and Western values in other cultures. As a result the youth thrive on a selfish, individualistic morality, family ties are broken, promiscuity increases and extramarital same-sex relations exacerbate the tendency to depopulation, immorality. Terrorism, crime, drug addiction devalue human life. The new means of mass destruction of humans appear rapidly. All these are natural results of the successful march of scientific and technological type of cultural development.

Against this background, the dramatic changes of values prevailing in the scientific and technical development paradigm, ethical regulators, objectives of social activity, are expected as well as in the goals of education.

It is necessary to change the understanding of nature as an object and resources for modernization activities, it is important to recognize and accept the person responsibility for all of the surrounding nature and the very existence of man. Within the framework of environmental ethics we have abandoned the idea of human domination over nature.

All this encourages us to discuss the emergence of a new (relative to the traditional, scientific and technological) stage of cultural development. Within its framework mankind has to solve environmental and other global problems that were generated by previous scientific and technological development. Deeper in the relationship with nature we are to consider the human factor, informational and creative possibilities of man, proceed to the dominance of intangible values, it is reasonable to limit the uncontrolled growth of the realenergy consumption, increase the consumption of information. Scientists talk about anthropocentric civilization (the basic idea of which is the presence of the human dimension in any knowledge about nature, society and the knowledge), as opposed to technocentrism.

Anthropocentric civilization will require not only technological development; it needs a serious spiritual transformation, revision of already well-established technological values in the Russian youth. It seems that these approaches are incompatible. However, the science of history teaches us that in the process of major social transformations there are prerequisites for the emergence of new ideological orientations. There are already visible sprouts of ideals of nonviolent strategy, the values of individual freedom, relying on the principles of environmental ethics and scientific rationality.

Therefore, the educational space of Russia should be substantially completed with target units of humanitarian component in its broadest sense, knowledge oriented worldview. So far, unfortunately, there is an inverse process.

Working out the future strategies for the development of educational space of Russia, aiming to restart the system of values - it is here a difficult, but most important issue. It is not accepted by the authorities yet. However, it is important in its setting. We need a constant critical analysis of currently used approaches.

Talking about values and goals in the context of education we have to recognize that international experience is already showing sprouts of "anthropocentric approach", which may be traced in the proposed by UNESCO classification of the main types of learning outcomes. Besides knowledge, including basic cognitive results achieved by all pupils (including reading literacy, writing, counting and subjects based on knowledge) such learning outcomes as formed values (solidarity, gender equality, tolerance, mutual understanding, respect for human rights, rejection of violence, the value of human life, self-esteem), and not just skills and competencies, but the possession of skills to solve problems, organize the experiment, team work, skills to live and interact with others, the ability to learn are suggested. This movement is in the direction of a new civilization.

It is important to understand that we have to avoid the mistake often committed lately, which is associated with the planting of the performance culture. There are non-formalized things in the educational space (e.g., values), which cannot be measured because the measurement process of values itself has immoral nature.

Evaluation of learning outcomes of students is a comprehensive assessment of the results (both formalized and non-formalized) of his/her education. The man in this case acts as the holder (bearer) of education. His/her evaluation takes place in terms "educated" or "uneducated" and "the learning outcome in this regard is education" [7].

Integrated effectiveness of education is a holistic assessment of the outcome of personal development - the result of human evolution as a person together with the acquisition of new properties, aspects, characteristics, personality traits: - moral, motivational, cognitive, creative, intellectual, physical, strong-willed, others.

The most important component of the assessment becomes a degree of awareness of the importance of personal values of education that involves individually motivated man's attitude to his own education.

The set of results, which the young man reaches at the time of interaction with the educational space looks 
like this: the result of the teaching (training) is a wide range of knowledge, the acquired skills and competencies. Upbringing outcomes include the result of education and self-education (breeding): coordination and mutual conditionality of knowledge, beliefs and behaviour; positive socially significant qualities of the person; the result of mental development (development of the mind, formation of mental functions, characteristics): independence of thought, reflexion, skills of self-control and self-regulation, creativity, sustainable motivation for knowledge, capacity for analysis, synthesis, speed of orientation in solving nonstandard tasks, speed and strength of the assimilation of new knowledge, critical mind, efficiency of thinking, etc.

The quality of education is evaluated through a comparison of the extent to which the result of a comprehensive education conforms to established, first and foremost, values, and as a result, conditions, rules and regulations [8].

One more important question is "for whom are educational goals needed and what kind of these goals?" The questions of who determines the goals of education, and for whom they are defined, certainly influence this choice strongly. While we consider knowledge, curricula and programs, the priority is of the professional teaching community. When it comes to education goals, the student obtains the dominant position and his aim is to reach the educational goals [9]. Formulation of the goals of education always inevitably affects the understanding of the quality of education, which itself depends on the interests, risk and success of student's learning. All of this seriously complicates the problem of choosing the goals of education in the economy of knowledge.

\section{Conclusion}

Summing up we can say that the current stage of cultural changes is aimed at fundamental transformation of the structure of the social division of labour, is connected with the transfer of the centre of attraction from the area of production to the area of information technology. Russia's leadership on the innovative direction is possible, first of all, on the basis of quality education, high-tech, cutting-edge research and development and improving the quality of public intelligence.

Renewal of education inevitably requires a new awareness of its objectives, the development and introduction of educational standards, obtaining a new quality of education in the new configuration of civilization.

Today we can say that, at a minimum, it is necessary to ensure the access to quality education services, using the deep target, structural and technological modernization, and the transition to a continuous individualized education for all, as opposed to the mass education system, characteristic for the industrial economy. In the professional and higher education a close relationship of education, science, business, and employers is useful (ignoring the fact that in the Russian mass reality it is not so much the relationship, but just words of love and faithfulness).

Of course, the actual function is to strengthen the humanitarian component of the educational space, a retreat from the technocratic orientation, and focus on the value of anthropocentric type of civilization

The purpose of the renewal of education should be focused on the transition from utilitarian and pragmatic education that is directed largely on acquiring knowledge, skills and competences, to the humanistic education for personal development. Humanistic education, when implemented, will ensure the formation of personality in which professionalism is inextricably connected with humanitarianism, careful attitude to the past, tolerance, pluralism, citizenship, creativity, social optimism, etc. In addition, it is important that the person takes a natural task of maintaining a high level of readiness for the restructuring of his/her social and professional functions in dynamically changing environment.

\section{References}

1. S.V. Ivanova, Tsennosti i Smysly, 2 (2012) [In Rus]

2. S.E. Shishov, The social and humanitarian research and technology, 3, 2 (2014) [In Rus]

3. S.V. Ivanova, Bulletin of the Russian Philosophical Society, 2 (2010) [In Rus]

4. S.V. Ivanova, Tsennosti i Smysly, 21, 5 (2012) [In Rus]

5. V.S. Stepin, Cognitive thinking and social action (Moscow, 2004) [In Rus]

6. A.J. Toynbee, A Study of History. Collection (Rolf, Moscow, 2001) [In Rus]

7. I.A. Zimnyaya, Pedagogical psychology (Logos, Moscow, 2001) [In Rus]

8. I.K. Orlov, Formation of teenagers in the conditions of civic activities for children and youth associations (Stavropol, 2006) [In Rus]

9. V.A. Kal'nei, S.E. Shishov, On the "teacher-student" education system of quality monitoring technology. (Moscow, 2000) [In Rus] 